\begin{tabular}{|c|c|c|}
\hline Received: March 2018 & Accepted: October 2018 & Published: October 2018 \\
\hline \multicolumn{2}{|c|}{ Article DOI: http://dx.doi.org/10.24903/sj.v3i2.201 } \\
\hline
\end{tabular}

\title{
Representation of Communicative Competence in English Language Textbooks in Indonesia
}

\author{
Ezis Japar Sidik \\ Universitas Sultan Ageng Tirtayasa, Indonesia \\ ezis.j.sidik@untirta.ac.id
}

\begin{abstract}
English textbooks play a paramount role in teaching process, and are expected to contain appropriate contents that can support students to acquire required competences for effective communication. The expected contents should contain different aspects of language abilities or competences well-known as communicative competence. Thus, the present study is aimed to explicate the representation of communicative competence aspects in the spoken dialogue instances contained in Indonesian EFL textbooks. Three English textbooks, prepared and designed under the auspices of the Indonesian Ministry of Education and Culture, are selected for the analysis. The findings suggest the textbooks have not provided sufficient dialogues that give useful models for students to use in communication. Amid the scarcity of the models, the available dialogues also do not much reflect how authentic spoken dialogues occur in real-life communication due to inadequacy to reflect real-life communication as insufficient representation of the communicative competence particularly in contained dialogue models.
\end{abstract}

Keywords: communicative competence, English, textbook dialogues, Indonesia 


\section{INTRODUCTION}

English as a foreign language (henceforth: EFL) policy in Indonesian education has not hitherto achieved satisfactory results although the policy has experienced some revisions and adjustments (Lie, 2007). The quality of educational (curriculum) policy and teacher competence is among the scapegoats for this stagnancy (Zein, n.d.). The curriculum policy is not always implemented as expected at practical level; for example, curriculum commitment to employ a communicative teaching approach is not interpreted consistently in EFL textbooks which are more likely based on a structural approach (Lie, 2007). In addition, teachers' lack of competence to provide more communicative tasks and materials in the classroom make them very reliant on the textbooks as their main teaching resources (Lie, 2007).

The use of textbooks as the kernel teaching resource in the EFL classroom is not only the case in Indonesia. It is maintained that the textbooks are in common usage in many other EFL classroom environments (See Nguyen, et al., 2016). The role of the course books as important teaching resources for both teachers and students is probably the most significant of all potential functions (See Cortazzi and Jin, 1999; Aliakbari, 2004). This function is in principle inevitable as the textbooks are deemed to be a 'hidden curriculum' (Canale, 2016) or a 'curriculum artefact' (Canale, 2016) which are considered to be an effective and practical tool to interpret educational policy into practical pedagogy (Matic, L., \& Gracin, 2016). Taking this into account, it is imperative that the utilization of textbooks in the EFL environment such as in Indonesia, should also concern with the quality of their contents in order to equip learners with essential language skills required for practical use, particularly in spoken communication. In the case where the quality of their contents is overlooked, the textbooks might function, not as a resource but instead as a restrictor or de-skiller (Sakai and Kikuchi, 2009; (Aliakbari, 2004).

It is said that effective English communication relies on one's ability to acquire aspects of communication well-known as communicative competence containing different aspects of language abilities or competences (Celce-Murcia, M., Dörnyei, Z., \& Thurrell, 1995). Thus, the textbooks will be meaningful for students when they contain these components of competence. The notion of communicative competence (hereinafter CC) generally attributed to Hymes (1972) has been revisited and adjusted with the most updated model proposed by (Celce-Murcia, 2007) to encompass at once sociocultural, discourse, linguistic, formulaic, interactional, and strategic competences. Until currently, no scholar has 
challenged the importance of CC itself particularly in EFL classroom settings although there might be some disagreements in regard to its contents/ components. Despite that these are inseparable and essential in a language teaching context, their consideration in EFL textbooks, particularly in the Indonesian context, is not much elaborated. Accordingly, the present study sets to probe the representation of CC in Indonesian EFL textbooks, based on that of Celce-Murcia's model with the main focus on spoken dialogue models provided for senior higher (secondary) level. The paper commences to discuss a brief notion of CC and its importance when considering EFL materials, and identifies how far this notion has been implemented in EFL textbooks. The paper continues to elaborate existing research on EFL materials in the Indonesian context. Afterwards, the analysis of Indonesian EFL textbooks is carried out to discover the extent to which they cover important aspects of CC. The discussion is thus concluded with pedagogical implications based on the results of analysis.

\section{Development of communicative competence}

The term "communicative competence" refers to a set of competences required to be capable of applying the language in real communicative use (Bagaric, V., \& Djigunovic, 2007). The notion of $\mathrm{CC}$ has received attentions from many scholars and has experienced some stages of evolution starting from Hyme (1972), (Canale, M., \& Swain, 1980), Canale (1983), Celce-Murcia, (Celce-Murcia, M., Dörnyei, Z., \& Thurrell, 1995), to (Celce-Murcia, 2007). The term itself was coined by Hyme $(1967,1972)$ who challenged Chomsky's concept on sole linguistic competence as pre-requisite to language performance (Gilmore, 2011) (Celce-Murcia, 2007); (Taha, W., \& Reishaan, 2008). According to him, instead of linguistic competence one also requires to consider sociolinguistic competence (social rules of language use in appropriate context) to be capable of using it in real-life communication (Celce-Murcia, 2007); (Leung, 2005). Hyme's original concept was further elaborated by (Canale, M., \& Swain, 1980) to cover three components of grammatical, strategic, and sociolinguistic competences before it was redeveloped three years after by Canale (1983) to include discourse competence in addition to the previous three components. More than a decade after Canale's model, Celce-Murcia, Dornyei, and (Celce-Murcia, M., Dörnyei, Z., \& Thurrell, 1995) revised the model by dividing Canale's sociolinguistic competence into sociocultural competence and actional competence in addition to linguistic, discourse, and strategic competences.

Afterwards, (Celce-Murcia, 2007) proposed an updated and revisited model of her and her colleagues' to become six types of competence, namely: sociocultural, discourse, 
linguistic, formulaic, interactional, and strategic competences (Celce-Murcia, 2007). CelceMurcia (2007, pp46-50) further elaborated the coverage of these domains along with subelements for each competence. At first, sociocultural competence refers to pragmatic knowledge of appropriate language use according to the social and cultural context of communication. The next one is discourse competence which is related to the selection, sequencing, and arrangement of words, structures, and utterances in order to create a unified message, particularly through the spoken mode. In addition, linguistic competence refers to basic elements of communication to include phonological, lexical, morphological, and syntactical patterns and types. The next one is considered to link with linguistic competence and is called formulaic competence. It refers to fixed and prefabricated chunks of language that are frequently used in daily communications. Afterwards, interactional competence is a bottom-up approach to top-down sociocultural approaches which include actional, conversational, and paralinguistic competences. Finally, strategic competence refers to knowledge of communicative strategies and how to use them. These strategies can be in forms of achievement of communicative goals, time-gaining strategies, self-monitoring, and interacting strategies.

In the language pedagogy, this notion has been used as a reference to justify and explicate new language approaches and teaching materials that are compatible with real-life communication as the goal of second/ foreign language pedagogy (Celce-Murcia, 2007). It has become a milestone of reform in language teaching practices from grammar-based and audio-lingual traditions into communicative language teaching (Celce-Murcia, M., Dörnyei, Z., \& Thurrell, 1995); Cramsch, 2006). These elements are considered inter-related in acquiring language proficiency for actual communication, as the knowledge of sentence-level grammar (linguistic competence) alone as proposed by (Chomsky, 1965) is far from being sufficient without, acquiring other competences (Leung, 2005); Savignon, 1985, p130). In addition, the only knowledge of grammar will be capable of using the language accurately linguistically, but will be problematic socio-culturally (Celce-Murcia, M., Dörnyei, Z., \& Thurrell, 1995). The concept is then found valuable in practical language pedagogy, such as in course-design, in order to ensure the achievement of language learning goals, namely the ability to use the language for actual communication (Shaw, 1992). In practice, (Gilmore, 2011), for example, has confirmed his study after conducting a 10-month longitudinal classroom-based experiment in Tokyo regarding the use of textbooks in comparison to the 
use of authentic materials in the EFL classroom, where the latter were more effective in developing the learners' communicative competence than the use of textbooks.

\section{Representation of communicative competence in English textbooks}

The $\mathrm{CC}$ is incomparable in providing authentic mirrors of real-life language use (Kataoka, K., Ikeda, K., \& Besnier, 2013). As the goal of EFL learning is generally to enable learners to use the language in real communication (Hedge, 2000); thus, teaching materials should reflect authentic use of language in practice. The representation of CC in EFL textbooks can provide students with 'real-world relevance which can help them link what they learn at school and how to use the language in practical communication' (Ozverir, I., Herrington, J., \& Osam, 2016); (Chan, 2013). Accrdingly, it is a necessity to balance all aspects of communicative competence in EFL course books in accordance to students' needs in communication.

The need to provide authentic representations of EFL contents to real language use is obvious (Chan, 2013), as being successful in practical use needs the minimal communication skills of receiving, understanding, and applying the substances of received lessons (Wiemann, J., \& Backlund, 1980); (Canale, M., \& Swain, 1980). The case is of primary importance in the EFL environment where the use of EFL textbooks often dominates resources in the classroom (See Nguyen at al. 2014; Lie, 2004; (Canale, 2016); (Landrum, R., Gurung, R., \& Spann, 2012) and where exposures to the target language is insufficient (Broughton, G., Brumfit, C., Flavell, L., Hill, P., \& Pincas, 1980). In practice, however, EFL materials are 'not yet developed systematically with reference to any well-defined and comprehensive communicative construct' (Celce-Murcia, M., Dörnyei, Z., \& Thurrell, 1995) (Gilmore, 2011) noted that although there are some improvements in quality compared to the past, current textbooks still provide learners with distorted and inaccurate representations of target language samples, which often fail to meet their communicative needs.

Other studies also provide consistent evidence. (Aliakbari, 2004) addressed the issues of intercultural competence which was not appropriately represented in Iranian textbooks. Although the textbooks still contained the culture of the target language, the proportion was considered inadequate and assumed not able to improve the students' intercultural competence (Aliakbari, 2004). Another study by (Mahboudi, H., \& Javdani, 2012) showed the perceptions of high school and university students who were mostly unsatisfied with the EFL contents of target language cultures in Iranian textbooks. In addition, (Chan, 2013) investigated the EFL textbook in Hong Kong with regard to the authenticity of written and 
spoken activities which showed in contrast to real-world language use. Likewise in China, the construction of cultural contents, particularly in primary school EFL textbooks, was mostly aimed at delivering the values and beliefs of the government and its political elites rather than at the skills the students require for effective communication (Liu, 2005). 


\section{English textbooks in Indonesian context}

Textbooks as main resources

The textbooks in use in the Indonesian context should meet the expectations of the curriculum which is currently in use called Curriculum 2013 (C-2013). This curriculum is promulgated as a strategic attempt to bring improvements to quality of the national education, in accordance with the current advancement of science and technology (Henceforth: MoEC, 2012). In regard to EFL policy, the C-2013 is developed on the basis of competence (MoEC, 2012, p4) that balances the knowledge and skill/ ability particularly in written and spoken aspects (Ministerial decree of education, 2016b). These two competences are then used as the basis of EFL textbook development.

In practice, the textbooks are heavily used in Indonesia as the English teaching and learning practices in the classroom are mostly driven by them (Supriadi, 2000 Cited in (Lie, 2007). As the textbooks are used to translate the curriculum policy into classroom practices (Ministerial decree of education, 2016a), the overuse of them is sometimes inevitable. Indeed, it is a requirement for teachers to use the textbooks which have met the criteria determined by the National Educational Standards Board (BNSP) as the main reference for teaching (Ministerial decree of education, 2016a). Among the required criteria, the textbooks should not contain materials which violate the principles of national values and beliefs, constitutions, and social norms (Ministerial decree of education, 2016b). As a result, the main textbooks in operation at schools are mostly written and published domestically; thus, the worldwide EFL textbooks are likely not to be considered for use as the main reference at least in public schools.

This significant and crucial role of textbooks in Indonesian schools is of great concern with regard to the quality of their contents in the attempts to achieve students' communicative goals, as previously noted. However, commercially published EFL course books available on the market, or those prepared by governmental (education) authorities have received some strident criticisms. For example, (Lie, 2007) found some inconsistences in interpreting curriculum expectations into textbook contents such as the case of the communicative approach being translated into a more grammatical approach in the textbooks. (Collins, 2006) also noted that the grammatical materials presented in the Indonesian EFL textbooks did not provide accurate information of English usage and there was an inadequate division between form and meaning and between class and function. Furthermore, Ekawati and Hamdani 
(2012) who investigated the representation of cultural contents in the textbooks found the target culture and the international culture were not well reflected in them.

\section{Dialogue models}

In the EFL environment, English is provided in schools, but it is not used in national and social lives (Broughton, G., Brumfit, C., Flavell, L., Hill, P., \& Pincas, 1980). The result is that learners are not adequately exposed to the target language in their social lives. In this situation, the classroom environment plays an important role in providing the required knowledge and skills in using language for communication. Learning the language particularly speaking skills is best acquired through conversation with classroom members in regard to different speech functions (Kramsch, 1993). Thus, the inclusion of sufficient dialogue models can be effective in providing exposure to the use of English in real interaction. In this regard, (Jones, M., Kitetu, C., \& Sunderland, 1997) maintained that dialogue activities provide helpful models of actual language uses which can realistically be carried out in the classroom.'

\section{METHODOLOGY}

\section{Research design and question}

The present study took a content analysis (Fairclough, 2003) probing the representation of communicative competence aspects in Indonesian EFL course books for senior secondary schools. The analysis was undertaken in two stages. At first, it sought to identify and explicate the representation of $\mathrm{CC}$ in the design and content of spoken texts, particularly in the form of dialogue as found in the EFL textbooks. Then, the next phase was to quantify its representation according to types and number of occurrences (Ramirez, A., \& Hall, 1990). The employment of this research design set to find out the answer to the question: How are the components of communicative competence represented in Indonesian EFL textbooks?

\section{Analysed materials}

The materials for analysis were taken from three Indonesian EFL textbooks prepared for grade X, XI and XII of senior secondary level which adopted a new curriculum design. These selected textbooks were prepared and designed under the auspices of the MoEC, and thus recommended for use in schools. These textbooks have also been through the evaluation process conducted by the existing national experts on EFL materials from some domestic 
universities. Accordingly, this selection was of significance, although there are potentially several other textbooks available in the market.

For the effectiveness, the data were only gathered from one productive skill, that of speaking, in order to measure if the textbooks have provided sufficient models of spoken communication. More specifically, the study focused its analysis on dialogue activities as found in the textbooks, considering that they act as 'oral models of actual language uses in the classroom' (Jones, M., Kitetu, C., \& Sunderland, 1997). Adequate inclusion of spoken communicative models was expected to develop pupils with the essential skills required for actual oral communication which was presumably noted as the most used skill for communication (Baleghizadeh, S., \& Shahri, 2014).

In general, these textbooks employed a functional syllabus as the materials were developed based on functional topics such as 'expressing intention' and 'visiting ecotourism destinations'. It was thus assumed that there should be more spoken models for different functional uses. However, these course books were considered not to contain many dialogue models and they were not always found in every chapter. For this reason, all dialogues available from the three course books were included for analysis when they fulfilled two simple criteria: they should contain at least four turn-taking exchanges and should be not part of classroom tasks. In the end, there were only 19 dialogues in total that met these criteria consisting of 5 models (Textbook X), 4 (Textbook XI), and 11 (Textbook XII).

\section{Proposed analysis}

The textbook analysis was carried out following the more recent concept of communicative competence proposed by (Celce-Murcia, 2007). As previously noted, the focus of the analysis was on a number of dialogues in these textbooks concerning the way in which the books considered $\mathrm{CC}$ aspects. The analysis was based on two aspects: the representation of each competence based on a number of occurrences and the proportion of sub-aspects from each competence. At the first stage, the dialogues were analysed if they contained six competences, as previously noted. Then, they were marked for any evidence indicating each aspect or sub-aspect competence, and unmarked for the absence of evidence. The scores were accumulated and converted into proportional percentages according to the number of dialogues.

The areas of analysis consisted of six areas of competence including their sub-themes (Celce-Murcia, 2007). The first was sociocultural competence where the focus of analysis was on three variables including social contextual, stylistic, and cultural factors. Afterwards, 
the discourse analysis consisted of three components of cohesion, deixis, and coherence. The next was linguistic competence with the focus of the analysis on two areas of morphological and syntactical aspects. Some other aspects of linguistic competence such as the phonological aspect were excluded for analysis as the data being assessed were in dialogue forms. Another aspect for analysis was the formulaic competence which focused on routine expressions, collocations, idioms, and lexical frames. For the interactional competence, the actional and conversational competences were two areas for analysis while the non-verbal/paralinguistic competence was out of the focus. The final analysis was the strategic competence which focused on achievement, stalling or time gaining, self-monitoring, and social strategies (Celce-Murcia, 2007).

\section{FINDING AND DISCUSSION}

As previously mentioned, this study is to investigate the representation of communicative competence components in spoken dialogue models as contained in Indonesian EFL textbooks. Table 1 shows the summary of its representation from the nineteen models in three textbooks. In the first instance, most dialogue models do not contain sociocultural competence, particularly regarding the social, contextual, stylistic and cultural factors. This aspect is only found in two dialogues from textbooks X and XI respectively, but a similar case is not evident from the textbook XII although more dialogues are doubled compared with the other two. With only $12 \%$ found to include sociocultural aspects, this competence becomes the least represented in the dialogues. Another aspect which is not well represented, but slightly better than the sociocultural, is strategic competence. As can be seen, the strategic aspects are only found in six dialogue models with its proportion only $32 \%$.

\begin{tabular}{ccccccc}
\hline Analysed & Sociocultural & Discourse & Linguistic & Formulaic & Interactional & Strategic \\
\cline { 2 - 7 } Textbooks & Number & Number & Number & Number & Number & Number \\
\hline I & $1\left(5^{*}\right)$ & 5 & 5 & 5 & 5 & 3 \\
II & $1\left(4^{*}\right)$ & 4 & 4 & 4 & 4 & 1 \\
II & $0\left(10^{*}\right)$ & 10 & 10 & 9 & 10 & 2 \\
\hline Percentage & 12 & 100 & 100 & 95 & 100 & 32 \\
\hline *number of dialogues for each analysed textbook; & & & &
\end{tabular}

Table 1 Representation of Communicative competence

Apart from these, other components are more represented in most dialogues. For example, most dialogues contain the formulaic aspects equal to $95 \%$ which is only absent from one dialogue. Other components such as discourse, linguistic, and interactional 
competences are also perfectly represented. Despite that, the proportion for each sub-theme is not given equal attentions as explicated in following paragraphs.

The first aspect of CC model is sociocultural. It is considered integral to language (Aliakbari, 2004); (Celce-Murcia, M., Dörnyei, Z., \& Thurrell, 1995); thus, the accommodation of this competence in textbooks is crucial. In this regard, (Celce-Murcia, 2007) suggested that making social and cultural blunder in oral communication is much more serious than making grammatical errors. Despite its importance, this aspect is often ignored in EFL materials in some different EFL contexts (Aliakbari, 2004); (Gilmore, 2004). A similar case also occurs in the Indonesian context as the current study has identified. As shown from Figure 1, the consideration of local cultures in the dialogues is very dominant, almost $90 \%$, while only $5 \%$ of the dialogues related to English speaking culture and another $5 \%$ related to foreign culture (French culture).This unbalanced proportion is not expected in raising students' cultural awareness. Although the local sociocultural contents are still necessary (Shin et al., 2011), the EFL materials are supposed to accommodate different social and cultural references in order to develop 'learners' attitudes and dispositions towards themselves and other communities (Ndura, 2004).

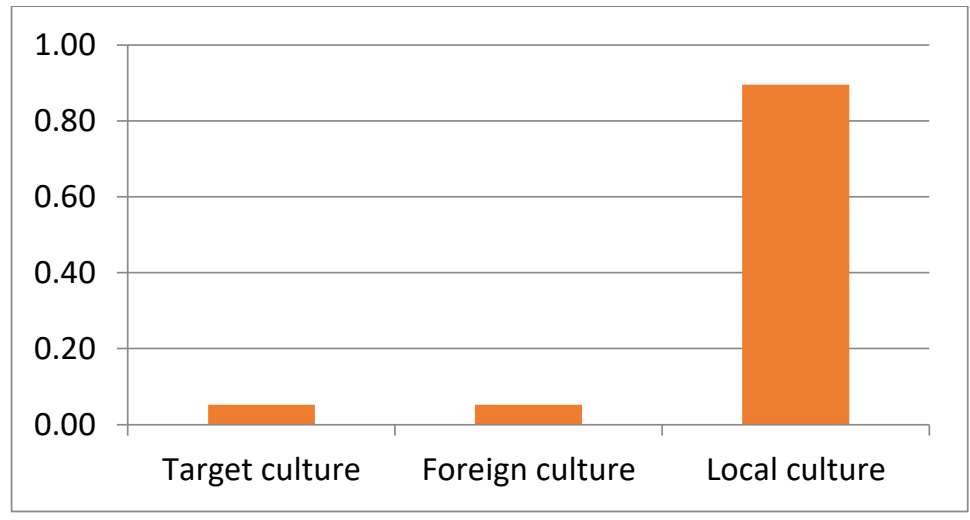

Figure 1 Representation of sociocultural competence

Almost similar to this case, strategic competence also lacks consideration in the dialogues. Only one third of them contain strategic expressions which are essential in spoken communication. There are only four occurrences concerning stalling and interacting aspects, but no evidence of compensatory and self-monitoring strategies is represented in any of the analysed dialogues (Figure 2). Although this competence is most likely acquired from direct experience during real communication (Stern, 1978 in (Canale, M., \& Swain, 1980), the knowledge of using such strategies can provide significant advantages at the first stages of 
language learning (Canale, M., \& Swain, 1980). Accordingly, the inclusion of this competence in textbooks is of high importance.

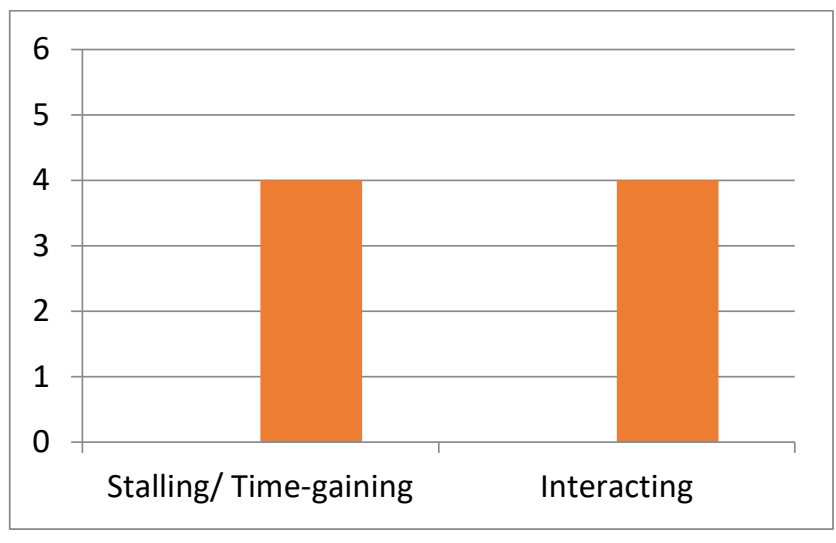

Figure 2 Representation of strategic competence

Another important aspect is discourse competence which is of paramount importance in order to achieve a unified spoken message from the produced utterances (Celce-Murcia, 2007). In addition, Gilmore (2007, p101) maintains that it has a critical aim in order to enable learners to 'produce unified, cohesive and coherent spoken or written texts in language use'. The current study shows that the textbooks have included this competence in the dialogue models. As Figure 3 shows, the dialogues have contained some sub-aspects of discourse competence although the proportion is different from one theme to another. The use of personal pronouns and anaphoric references are, for example, sufficiently exemplified in the dialogues, but not the use of ellipsis-construction and cataphoric references.

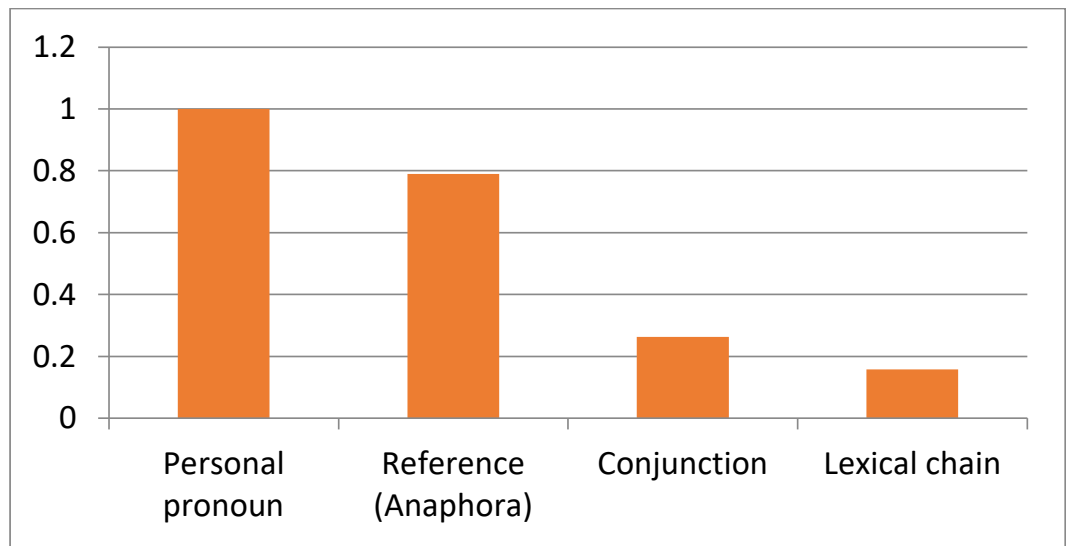

Figure 3 Representation of discourse competence 
The next component is linguistic competence which is well represented in the textbooks. Indeed, its representation is the main strength of the textbooks. The dialogues contain most aspects of linguistic aspects both morphologically and syntactically. Despite that, the contents of some grammatical aspects outweigh the others (Figure 4). For instance, all dialogues contain adequate examples of language inflectional processes, but insufficient samples of the derivational process which are only evident in two dialogues. Interestingly, these derivational tokens are only evident from the use of authentic dialogues. Likewise, adequate samples of certain syntactical components are provided in the dialogues with the basic sentence structures and canonical word-orders as the two most dominant cases. However, the embedding sentence construction, and in the particular the marked word-orders (object fronting instead of subject) are out of the authors' consideration. Although the textbooks have accommodated the linguistic aspects well, balanced proportions of different grammatical components are still poor.

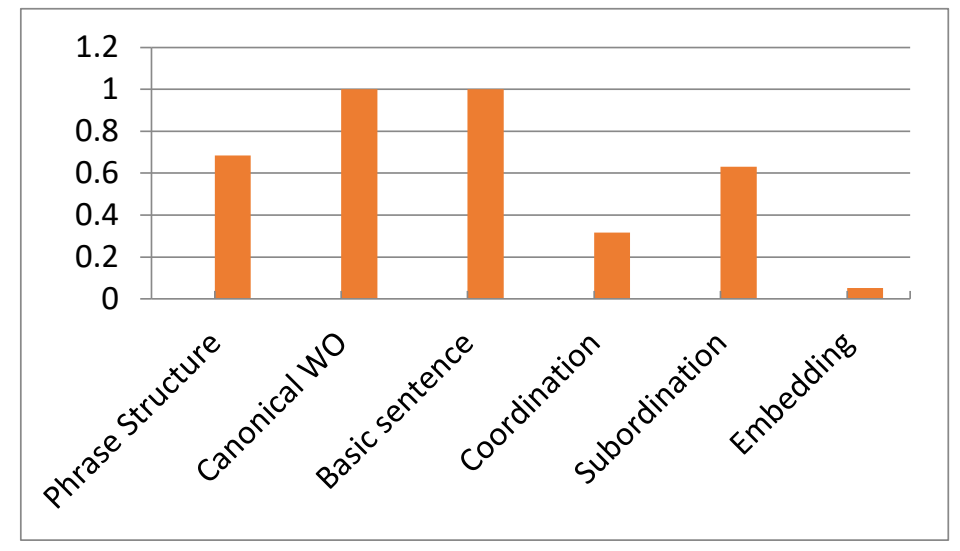

Figure 4 Representation of syntactical aspects

Partly related to the linguistic aspect is formulaic competence. This competence has received a growing interest in EFL materials, as its usage in communication is considered as important as linguistic usage (Hunston, 2002 in (Celce-Murcia, 2007). In this regard, the study has found that most dialogues contain this aspect although the proportion is still not significant (Figure 5). The representation of its sub-themes is not adequate where its contents are more dominated with routine phrases and 'adjective-noun' collocations, while the samples of idioms, lexical frames, and other forms of collocations are not much exemplified. None of them contains in made-up dialogues but in the two authentic dialogues. 


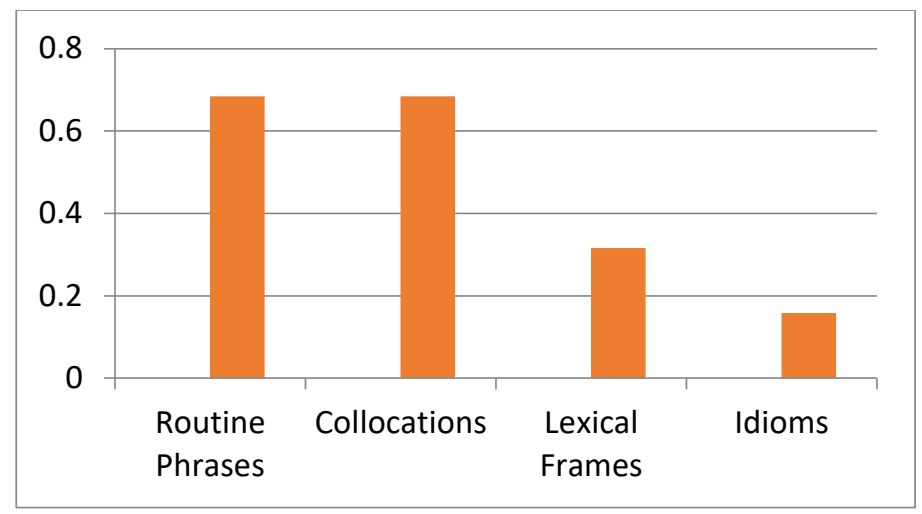

Figure 5 Representation of formulaic competence

The last relates to interactional aspects which are represented in all dialogues although the proportion between elements is considered unequal. As shown in the table 6a, only two aspects of it are represented in more than $50 \%$ of the total dialogues (interpersonal and information exchange), while functional expressions such as giving suggestions, opinions, feelings, and regret are represented in around $30 \%$ or less. Although different functional expressions have been provided, fair proportion of these examples should be of main consideration for the authors.

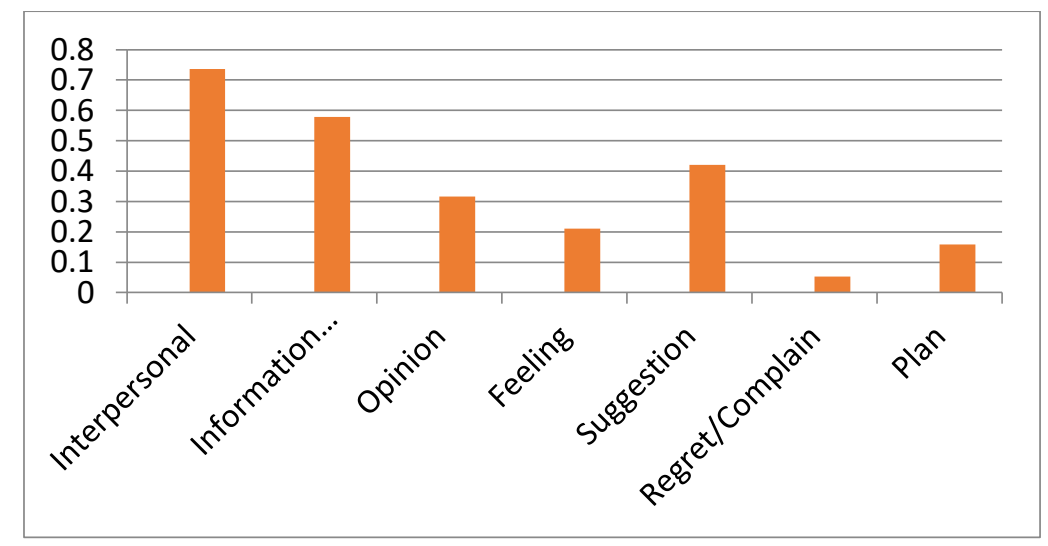

Figure 6a Representation of actional competence

Fair representation is also a similar issue in the interactional competence. As evident from the table $6 \mathrm{~b}$, maintaining talk is the most represented in the dialogues with $63 \%$, while backchannelling and opening/closing talks are represented in less than 50\%. Main criticism from the available dialogues is that they do not provide actual models of real conversation. For example, many dialogues only give examples of opening talks instead of giving both opening and closing examples. Indeed, the textbooks still lack adequate contents of language 
use in different functional contexts as commonly occurred in real communication (CelceMurcia, M., Dörnyei, Z., \& Thurrell, 1995).

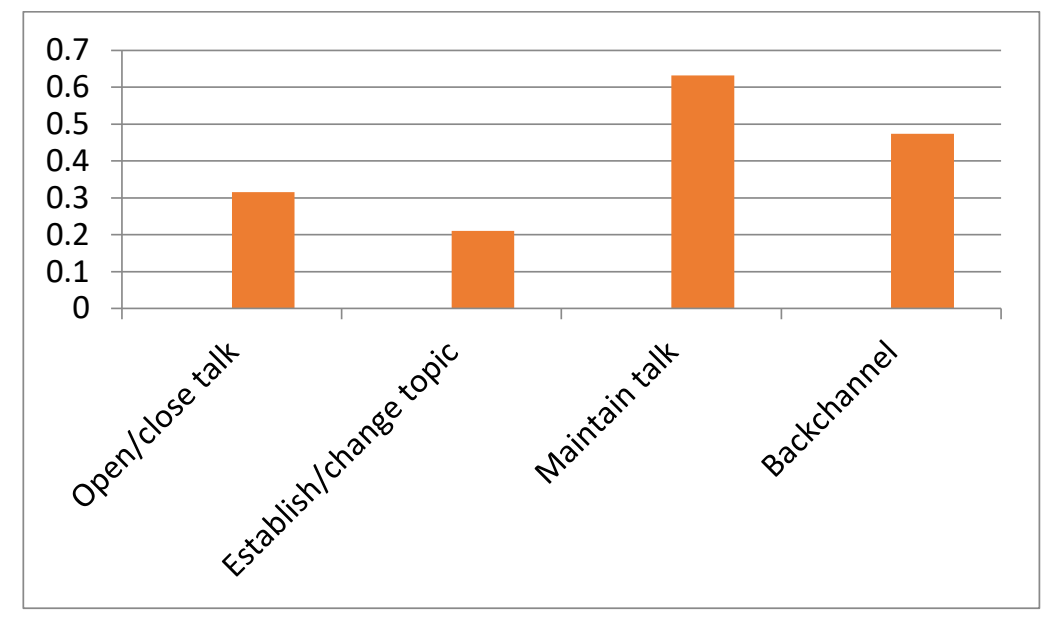

Figure 6b Representation of conversational competence

\section{Pedagogical Implications}

The recognition of English as the international language (Shin et al. 2011) has called for the importance of English communicative skills. It is noted that communication skills in the current competitive world are the most sought after quality of an educated person; thus being able to communicate effectively is the most important of all language skills (Gerald, 2015). Accordingly, English has become integral in educational policy in many EFL contexts (Copland, F., \& Garton, 2014). The policy of introducing English from primary education is evident in some countries (See Nguyen et al. 2014) in order to equip learners with better language skills required for effective communication. Indonesia, although it has not set English as a compulsory subject at primary level, also considers the essential role of English for the students. It becomes one of the main subjects at secondary levels and is included to be tested in national examination (Law No. 32, 2013).

The employment of learner-centred approach, as the case in many EFL contexts, is an important commitment to develop students' communication skills. However, in order for this approach to have better impacts in developing communication skills, the quality of the language materials/ textbooks is also essential. The textbooks are supposed to cover the systematic and comprehensive communicative competence construct (Celce-Murcia, M., Dörnyei, Z., \& Thurrell, 1995) which should be based on and respond to students' communication needs (Canale, M., \& Swain, 1980). One of the essential needs is for the textbooks to provide ample opportunities for the learners to take part in meaningful 
communicative interaction which is realistic, in the language classroom (Canale, M., \& Swain, 1980); thus in doing so, the availability of authentic dialogue models will give helpful guidance to the students. Considering that CC consists of interrelated aspects of sociocultural, discourse, linguistic, formulaic, interactional, and strategic competences, their considerations in the EFL textbooks should be an important concern for many textbook authors.

However, as the findings of this study have showed that the textbooks have not contained sufficient dialogues in regard to adequacy and quality. There were insufficient examples of dialogues with only 19 models with five, four, and eleven models in respective textbook. In addition, the dialogues have not reflected the authentic mirrors of spoken dialogues which usually occur in real communication, but intuitively made-up dialogues with local cultural contents are more dominant. Based on these findings, some suggestions are recommended in order that the textbooks will provide better supports for learners' communication skills.

First, more dialogue models which capture more authentic interactions are required in EFL course books. Since the learners are unlikely to have access to English exposures in their social lives, the classroom is then the most realistic place to practice the language as 'one of the best ways of learning a foreign language is through conversation among students' (Kramsch, 1993). Thus, the dialogue models are essential clues as to how dialogues are supposed to work, in accordance with real-life practice. Second, the textbooks require a balance between local, target and foreign cultures in order to provide experiences for students to be part of global community. Such mixed cultural contents are important as 'language learning is learning how to communicate as a member of a particular sociocultural group (Breen and Candlin, 1980 cited in (Kramsch, 2006). Third, the textbooks are also expected to consider different types of language registers particularly casual/informal registers in different functional settings. The analysed dialogues are mostly set under formal/ semiformal situations with much emphasis on a rigid use of grammatical rules. When this situation is maintained, there is the possibility of providing misleading information to the students regarding the dominant role of grammar in real spoken communication. Therefore, providing casual conversation models will probably minimise their reliance on the rules of grammar and start to realise other components beyond grammar. 


\section{CONCLUSION}

This paper investigated the representation of communicative competence in dialogue models as parts of the Indonesian EFL textbook materials. Generally speaking, the textbooks have not provided sufficient dialogues that would give helpful models for the students to use in interaction. In addition, the dialogues provided in these textbooks do not much reflect how authentic spoken dialogues occur in real-life communication. This poor reflection of real-life communication stems from the inadequate representation of $\mathrm{CC}$ in the dialogue models, particularly regarding the sociocultural and strategic aspects. In accordance with this, the textbooks need to provide more dialogue models which reflect the authentic mirrors of real spoken interaction. In so doing, the notion of communicative competence can be a useful construct for better development of the EFL textbook contents and can thus improve the quality of language teaching. 
Aliakbari, M. (2004). The place of culture in the Iranian ELT textbooks in high school level (9th Pan-Pacific Association of Applied Linguistics Conference). Cheonan - South Korea.

Bagaric, V., \& Djigunovic, J. (2007). Defining communicative competence, 8(1), 94-103.

Baleghizadeh, S., \& Shahri, M. (2014). EFL teachers' conceptions of speaking competence in English. Teachers and Teaching: Theory and Practice, 20(6), 738-754.

Broughton, G., Brumfit, C., Flavell, L., Hill, P., \& Pincas, A. (1980). Teaching English as a foreign language (2nd ed). London: Routledge.

Canale, M., \& Swain, M. (1980). Theoretical bases of communicative approaches to second language teaching and testing. Applied Linguistics, 1(1), 1-47.

Canale, G. (2016). (Re)searching culture in foreign language textbooks, or the politics of hide and seek. Language, Culture and Curriculum, 29(2), 225-243.

Celce-Murcia, M., Dörnyei, Z., \& Thurrell, S. (1995). Communicative competence: A pedagogically motivated model with content specifications. Issues in Applied Linguistics, 6(2), 5-35.

Celce-Murcia, M. (2007). Rethinking the Role of Communicative Competence in Language Teaching. (Dordrecht: Springer, Ed.), Intercultural Language Use and Language Learning. Safont Jordà (Eds.).

Chan, J. (2013). The role of situational authenticity in English language textbooks. RELC Journal, 44(3), 303-317.

Chomsky, N. (1965). Aspect of the Theory of Syntax. Cambridge: Mass: MIT Press.

Collins, P. (2006). Grammar in TEFL: A critique of Indonesian high school textbooks. TEFLIN Journal, 17(1), 1-10.

Copland, F., \& Garton, S. (2014). Key themes and future directions in teaching English to young learners: Introduction to special issue. ELT Journal, 68(3), 223-230.

Fairclough, N. (2003). Analyzing discourse: Textual analysis for social research. London: Routledge.

Gerald, R. (2015). The World beyond the Classroom: 21st Century Education, Technology and 4Cs. Retrieved from https://storify.com/RebeccaG27/4cs-in-education

Gilmore, A. (2004). A comparison of textbook and authentic interactions. ELT Journal, 58(4), 363-374.

Gilmore, A. (2011). "I prefer not text": developing Japanese learners' communicative competence with authentic materials. A Journal of Research in Language Studies, 61(3), $786-819$.

Hedge, T. (2000). Teaching and Learning in the Language Classroom: A guide to current ideas about the theory and practice of English language teaching. Oxford: Oxford University Press.

Jones, M., Kitetu, C., \& Sunderland, J. (1997). Discourse roles, gender and language textbook dialogues: who learns what from John and Sally? Gender and Education., 9(4), 469-490.

Kataoka, K., Ikeda, K., \& Besnier, N. (2013). Decentering and recentering communicative competence. Editorial of Language and Communication, 3(3), 345-350.

Kramsch, C. (1993). Context and culture in language teaching. Oxford: Oxford University Press.

Kramsch, C. (2006). From communicative competence to symbolic competence. The Modern Language Journal, 90(2), 249-252.

Landrum, R., Gurung, R., \& Spann, N. (2012). Assessment of textbook usage and the relationship to student course performance. College Teaching, 60, 17-24.

Leung, C. (2005). Convival communication: recontextualizing communicative competence. International Journal of Applied Linguistics, 15(2), 119-142. 
Lie, A. (2007). Education policy and EFL curriculum in Indonesia: between the commitment to competence and the quest for higher test scores. TEFLIN Journal, 18(1), 1-14.

Liu, Y. (2005). The construction of cultural values and beliefs in Chinese language textbooks: a critical discourse analysis. Discourse: Studies in the Cultural Politics of Education, 26(1), 15-30.

Mahboudi, H., \& Javdani, F. (2012). The teaching of English in Iran: The place of culture. Journal of Language and Culture, 2(5), 87-95.

Matic, L., \& Gracin, D. (2016). The use of the textbook as an artefact in the classroom: A case study in the light of a socio-didactical tetrahedron. J Math Didakt, 37, 349-374.

Ministerial decree of education. Buku yang digunakan oleh satuan pendidikan [Textbooks to be used by schools]. (2016). Jakarta: Ministry of Education and Culture.

Ministerial decree of education. Kompetensi inti dan kompetensi dasar pelajaran pada Kurikulum 2013 [Main competence and basic competence of subjects based on Curriculum 2013] (2016). Jakarta: Ministry of Education and Culture.

Ndura, E. (2004). ESL and cultural bias: An analysis of elementary through high school textbooks in the western United States of America. Language, Culture and Curriculum, 17(2), 143-153.

Ozverir, I., Herrington, J., \& Osam, U. (2016). Design principles for authentic learning of English as a foreign language. British Journal of Educational Technology, 47(3), 484493.

Ramirez, A., \& Hall, J. (1990). Language and culture in secondary level Spanish textbooks. The Modern Language Journal, 74(i), 48-65.

Taha, W., \& Reishaan, A. (2008). The Relationship between Competence and Performance: Towards a Comprehensive TG Grammar. Adab Al - Kufa Journal, 1(2), 35-59. Retrieved from http://www.iasj.net/iasj?func=fulltext\&aId=42292

Wiemann, J., \& Backlund, P. (1980). Current theory and research in communicative competence. Review of Educational Research, 50(1), 185-199.

Zein, S. (n.d.). Pre-service education for primary school English teachers in Indonesia: policy implications. Asia Pacific Journal of Education, 36(1), 119-134. 